\title{
Developing a sustainability science approach for water systems
}

\author{
Christa Brelsford $^{1}, \underline{\text { Marion Dumas }}^{2}$, Edella Schlager $^{3}$, Brian J. Dermodv $^{4}, \underline{\text { Michael Aiuvalasit }}^{5}, \underline{\text { Melissa R. Allen-Dumas }}^{6}$, Janice $^{\text {Ben }}$

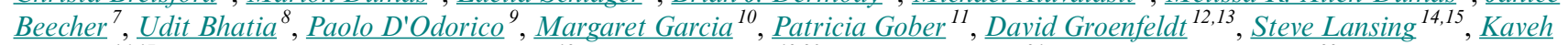 \\ $\underline{\text { Madani }}{ }^{16,17}$, Linda Estelí Méndez-Barrientos $^{18}$, Elena Mondino ${ }^{19,20}$, Marc F. Müller $^{21}$, Frances C. O'Donnell $^{22}$, Patrick M. Owuor $^{23}$, \\ James Rising ${ }^{2}$, Matthew R. Sanderson ${ }^{24}$, Felipe A. A. Souz $^{25}$ and Samuel C. Zipper ${ }^{26}$
}

ABSTRACT. We convened a workshop to enable scientists who study water systems from both social science and physical science perspectives to develop a shared language. This shared language is necessary to bridge a divide between these disciplines' different conceptual frameworks. As a result of this workshop, we argue that we should view socio-hydrological systems as structurally coconstituted of social, engineered, and natural elements and study the "characteristic management challenges" that emerge from this structure and reoccur across time, space, and socioeconomic contexts. This approach is in contrast to theories that view these systems as separately conceptualized natural and social domains connected by bi-directional feedbacks, as is prevalent in much of the water systems research arising from the physical sciences. A focus on emergent characteristic management challenges encourages us to go beyond searching for evidence of feedbacks and instead ask questions such as: What types of innovations have successfully been used to address these challenges? What structural components of the system affect its resilience to hydrological events and through what mechanisms? Are there differences between successful and unsuccessful strategies to solve one of the characteristic management challenges? If so, how are these differences affected by institutional structure and ecological and economic contexts? To answer these questions, social processes must now take center stage in the study and practice of water management. We also argue that water systems are an important class of coupled systems with relevance for sustainability science because they are particularly amenable to the kinds of systematic comparisons that allow knowledge to accumulate. Indeed, the characteristic management challenges we identify are few in number and recur over most of human history and in most geographical locations. This recurrence should allow us to accumulate knowledge to answer the above questions by studying the long historical record of institutional innovations to manage water systems.

Key Words: institutions; socio-hydrology; water systems

\section{INTRODUCTION}

Water has always been one of humanity's most fundamental resources and, simultaneously, a potential threat. Indeed, water's natural spatio-temporal variability has made it a constraint on economic activity, has posed threats to capital assets, and has provided pathways for disease since sedentary settlements first appeared. Water is fundamental to the organization of human societies because most human uses of water require collective management. The resulting interactions among the social, engineered, and natural aspects of water systems generate challenges around managing flood risk, drought consequences, and water quality. We note that these challenges have consistent characteristics across diverse social, economic, and technical contexts, and so we call them "characteristic water management challenges". These challenges have been drivers of innovation in water institutions through millennia of human history. We argue that their recurrence and the multiplicity of institutional innovations that arose to address them over long historical time reveal general patterns of coupled social and hydrological system dynamics. Studying these patterns leads to a research program that can accumulate knowledge across cases and enhance the understanding of the institutional innovations needed to adapt to an uncertain future, both for water problems and for sustainability problems more generally.

Interdisciplinary research in water systems has frequently used approaches from hydrology and engineering combined with approaches from economics and other behavioral sciences. It has not often capitalized on strategies that take a broader institutional lens, such as from the social-ecological systems literature or political science. However, some aspects of water system research, particularly its long history of recognizing the deep coupling between hydrological states and collective social behavior, can also generate useful strategies for social-ecological systems research. We believe that looking for regular patterns in institutional behavior and how these patterns recur in different contexts can contribute to a more generalizable understanding of socio-hydrological systems.

\footnotetext{
${ }^{1}$ Human Dynamics Group, Oak Ridge National Laboratory, ${ }^{2}$ Grantham Research Institute, London School of Economics, ${ }^{3}$ School of Government and Public Policy, University of Arizona, ${ }^{4}$ Copernicus Institute of Sustainable Development, Utrecht University, ${ }^{5}$ Illinois State Archaeological Survey, University of Illinois at Urbana-Champaign, ${ }^{6}$ Computational Urban Sciences Group, Oak Ridge National Laboratory, ${ }^{7}$ Michigan State University, ${ }^{8}$ Civil Engineering, Indian Institute of Technology Gandhinagar, ${ }^{9}$ Department of Environmental Science, Policy, and Management, University of California Berkeley, ${ }^{10}$ School of Engineering and the Built Environment, Arizona State University, ${ }^{11}$ School of Geographical Sciences and Urban Planning, Arizona State University, ${ }^{12}$ Water-Culture Institute, ${ }^{13}$ Department of Anthropology, University of New Mexico, ${ }^{14}$ Santa Fe Institute, ${ }^{15}$ Complexity Science Hub Vienna, ${ }^{16}$ Department of Political Science and The MacMillan Center for International and Area Studies, Yale University, ${ }^{17}$ Centre for Environmental Policy, Imperial College London, ${ }^{18}$ Department of Environmental Science and Policy, University of California Davis, ${ }^{19}$ Department of Earth Sciences, Uppsala University, ${ }^{20}$ Centre of Natural Hazards and Disaster Science, Sweden, ${ }^{21}$ Department of Civil and Environmental Engineering and Earth Sciences, University of Notre Dame, ${ }^{22}$ Department of Civil Engineering, Auburn University, ${ }^{23}$ Department of Anthropology and Global Health, Northwestern University, ${ }^{24}$ Department of Sociology, Kansas State University, ${ }^{25}$ São Carlos School of Engineering, University of São Paulo, ${ }^{26}$ Kansas Geological Survey, University of Kansas
} 


\section{MOTIVATION AND METHODS}

This paper is a synthesis of ideas that arose from an interdisciplinary workshop entitled "Modeling and Measuring Socio-Hydrological Dynamics Across Scales", held at the Santa Fe Institute in June 2018. The motivation for holding this workshop was to develop a more integrated understanding of how social, institutional, and economic activities influence water outcomes, both human and environmental. These outcomes include both how productively, fairly, and sustainably water is used, and the consequence of those choices on hydrological outcomes such as flood risk, groundwater depletion, or water quality. Authors Brelsford and Dumas saw a great difference in framework and language between the social science literature (including from social-ecological systems) and the literature on water systems and water resources, developed by hydrologists. The water systems literature has made great strides in incorporating human factors in its analyses (e.g., Davies and Simonovic 2011). However, it uses a restricted view of human agency, in the form of using fairly deterministic rules for the dynamics of populationlevel variables or for individual-level behaviors (e.g., Elshafei et al. 2014, Gohari et al. 2017) or focusing on decision-theoretic frameworks for management (Merz et al. 2015). It does not typically integrate institutions and collective decision making (with the important exception of the subfield of water conflict, which makes use of game theory to analyze conflicts, e.g., Madani et al. 2014). In contrast, the social science literature related to water tends to describe, in great detail, the social arrangements developed to manage water on a case-by-case basis (e.g., Heikkila et al. 2011, Lubell et al. 2014), but with little systematic or deep connection to the hydrological outcomes deemed important by hydrologists and water managers.

We organized the workshop to explore this gap and to attempt to build a common set of questions between fields concerned with water systems. Workshop attendees were roughly equally distributed between the social sciences and natural sciences (including political science, economics, sociology, anthropology, hydrology, and engineering). The workshop's 23 attendees were gender balanced, came from five continents, and ranged from graduate students to senior scientists, all with research that focuses on water systems. Workshop time was balanced between informal, small-group discussion of early stage research ideas and plenary sessions focused on identifying shared research goals across the various intellectual communities represented. The plenary sessions explored drivers of water supply, demand, and allocation conflicts on different temporal and spatial scales. In the informal sessions, researchers worked in small groups, contributing ideas to each other's existing research in light of the important questions identified in the plenary sessions. Methodological opportunities and challenges identified in the informal sessions also fed back in plenary sessions explicitly focused on methodological and empirical questions.

The diversity of backgrounds and approaches represented at the workshop allowed us to extract shared ideas that we think can help unify and move the study of water systems forward. One of our main conclusions is that we can integrate institutions into hydrological modeling by asking different questions of the modeling effort and by identifying recurring patterns. We think that this reorientation may help socio-hydrology to move away from predicting long-term dynamics and instead work toward analyzing how hydrological, economic, and institutional factors interact to affect the resilience and adaptability of such systems. Within the social sciences, a focus on recurrent management problems can help to accumulate better knowledge across cases.

CHARACTERISTIC WATER MANAGEMENT PROBLEMS

Over recent decades, researchers have sought quantitative theories to describe the behavior of coupled human and physical systems (Holling 1973, Anderies et al. 2004, Liu et al. 2007, Olsson and Jerneck 2018). This literature notes that inherent features such as nonlinearity, inter- and intradependencies, nonstationarity, hysteresis, and multiple objectives call for strategies to describe and predict these system behaviors that are distinct from the empirical strategies used successfully to explore natural and ecological systems independent of human activities. Despite substantial effort (Anderies 2015, Preiser et al. 2018, Schlüter et al. 2019), quantitative frameworks that describe the behavior of coupled human and physical systems are still limited. We propose that seeking generality across management challenges (as is done, for example, by Srinivasan et al. 2012), rather than across modeling problems, will help to advance sustainability science and policy.

What do we mean by generality across management challenges? We claim here that water problems in different places and different times resemble each other, and that this resemblance should allow us to gain generalizable knowledge about socio-hydrological systems' behaviors and management strategies. For example, where water scarcity is a threat, the characteristic management challenges generally concern allocation and the long-term (im) balance of supply and demand. Successful management generally centers around the allocation of water rights or access to water across people, economic sectors, and ecological uses (Brewer et al. 2007, Coman 2011). Sustainable water management also calls for addressing the intertemporal and spatial dynamics of water consumption in relation to reservoir or groundwater depletion (Fishman et al. 2011). When too much water is a threat, institutional challenges generally concern the distribution of flood risk and water damage across space and social groups. Impacts are influenced by flood mitigation, coastal protection, and various forms of green infrastructure. Choices and policies about the physical location of human activities affect the distribution and impacts of risk across social groups, economic sectors, and ecosystems (Li et al. 2016, Di Baldassarre et al. 2018, Quinn et al. 2018). Water quality can be impaired by biological (e.g., pathogens), geochemical (e.g., nutrients or pollutants), and thermal (e.g., heat release) disturbances. When water quality is a problem, an important institutional challenge is how to manage the deep causal uncertainty and ignorance about the cumulative impacts of these disturbances, which tend to interact in complex ways and amplify over time (Beck 1987, Polasky et al. 2011, Hering et al. 2015). Further challenges include the allocation of pollutant loads and the monitoring and enforcement of these allocations given the diffuse nature of nonpoint source pollution (Scholz and Wang 2006, Xepapadeas 2011).

A research program focused on water management challenges stands a better chance of deeply integrating knowledge from different disciplines. It can also organize research to accumulate knowledge successfully, thanks to the reoccurrence of these challenges in space and over a long stretch of history, making it 
Fig. 1. Water systems are a distinct class of coupled systems because they present a finite set of recurrent management challenges: disturbances of too much, too little, or wrong-quality water. These challenges can manifest alone or in combination at different temporal and spatial scales and have differential impacts within and across social groups. Thus, water systems provide us with a long historical record of institutional innovation in response to management challenges at increasingly large scales of social organization, from small farming settlements to nation states.

elements that co-constitute socio-hydrological systems characteristic management problems consequence domains

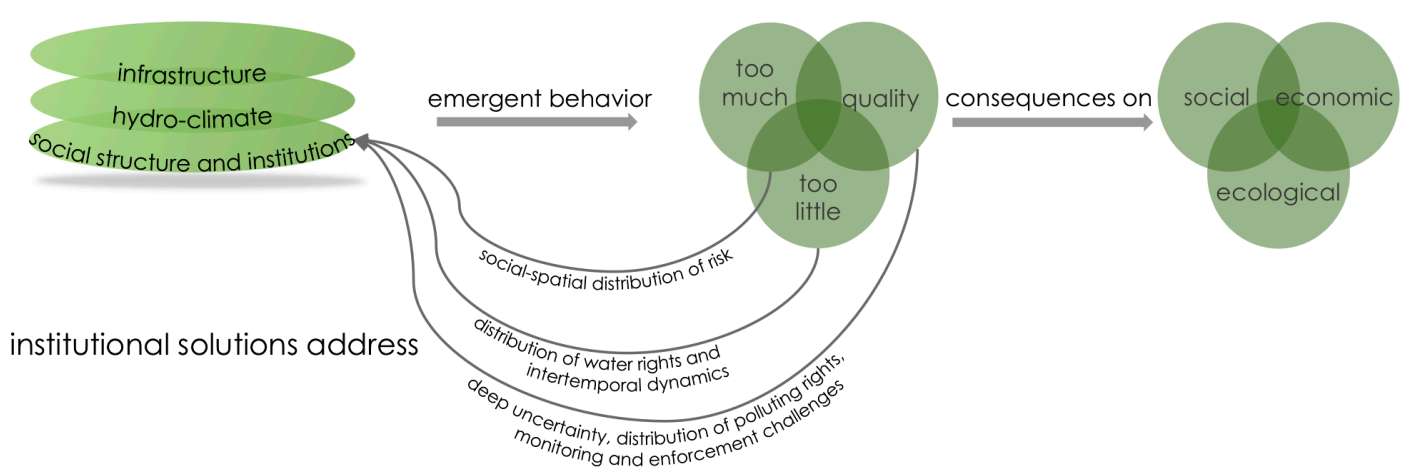

possible to draw systematic comparisons. In contrast, focusing on modeling problems tends to lead to more siloed research streams that ignore important dimensions of the systems. For example, the current socio-hydrology literature models human behavior in the framework of differential equations. This implicitly leads scientists to model average behavior, leaving out heterogeneity in individual behavior as well as collective decisions and institutions. As another example, much work in political science and public policy focuses on modeling and measuring cooperative behavior without necessarily having a clear representation of the water problem to be solved (Fig. 1).

\section{GENERAL LESSONS FROM HISTORICAL INSTITUTIONAL INNOVATIONS}

The study of both modern and historical coupled social and hydrological systems yields a wealth of strategies, some successful, to address these characteristic problems. Ancient water managers developed institutions and technologies capable of robustly coping with semiarid and highly variable climatic conditions (Nelson et al. 2010). They developed solutions to co-occurring problems, including complementary arrangements to govern water withdrawals and the provisioning of water infrastructure (Ostrom 1993) or fine-tuned patterns of cropping that simultaneously address water needs and other ecological variables (Lansing et al. 2017). Historical studies also inform us about the rates of adaptation to the changing availability of water (Hornbeck and Keskin 2014), as well as constraints to adaptation in the absence of storage infrastructure (Brown and Lall 2006). The historical record offers fantastic examples of how institutions are shaped by environmental conditions, for example, the gradient of water institutions from the humid American East to the dry American West (Libecap 2011) or the resilience of pastoral communities to the variable ecological conditions of dryland environments (Boone 2014). These examples of historical institutional and socio-technical innovations demonstrate the broad range of strategies and socio-technical transition pathways that are observed when socio-hydrological systems respond to shocks and disruptive change (Geels and Schot 2007). Crucially, an emerging research agenda addresses the mechanisms by which humans sometimes succeed and sometimes fail to modify institutions as water availability or patterns of water usage change (Garrick et al. 2013, Elshafei et al. 2014, Sivapalan and Blöschl 2015).

Despite millennia of human experiments, the management of coupled social and hydrological systems is in need of innovation from practitioners and scientists. Old problems have become more acute and new problems have emerged because of: (1) economic and population growth, (2) anthropogenic climate change, (3) an increasing recognition of the previously unaccounted-for water needs of both disadvantaged communities and ecosystems, and (4) the growing complexity of interbasin and cross-scale interactions, due to trade, large-scale infrastructure, and land-use change patterns. We also need to manage the distribution of water availability and risk for users of different socioeconomic characteristics, rather than merely focus on aggregate or average availability and risk (Brelsford et al. 2017). There are many studies of inequality of water access and contaminant exposure in the environmental justice literature and development literature (Tisdell 2003, Baisa et al. 2010). There are also studies about the conflict between urban and agricultural uses of water (Flörke et al. 2018), and the social-ecological systems literature has focused on resource allocation in common-pool resource problems (Ostrom 1993). However, analyzing the distribution of water quantity and quality across society is not currently a routine part of hydrological modeling (Zeitoun et al. 2016). These trends mean that social processes must now take center stage in the study and practice of water management for all fields. Given today's challenges, now is a critical time to extract general lessons from the historical record of institutional innovation. 


\section{QUESTIONS FOR FUTURE RESEARCH}

To draw lessons from history and to devise sensible approaches for the future, more consistent and commonly shared framing of characteristic challenges is needed. In the past, much sociohydrology research has focused on modeling problems framed by different scientific domains and their modeling techniques, followed by attempts to couple the models using two-way feedbacks between the physical and social components (e.g., Di Baldassarre et al. 2013). Alternatively, we can view sociohydrological systems as structurally co-constituted of natural, engineered, and social elements, and think of characteristic problems as phenomena emerging from this structure. For example, the conjunction of allocated property rights and landscape and hydroclimatic features results in a given spatiotemporal distribution of water. This perspective goes beyond searching for evidence of feedbacks between the separately conceptualized natural and social domains, as has been the focus in the field of socio-hydrology (e.g., Di Baldassarre et al. 2015). Instead, it encourages us to explore questions such as: What methods have failed or succeeded in addressing these challenges? What structural components of the system affect its resilience to hydrological events and through what mechanisms? Are there differences between successful and unsuccessful strategies to solve one of the characteristic management challenges? If so, how is success affected by institutional structures, socioeconomic context, and ecological conditions? How do people perceive hydrological risk, and how do perceptions change with changing natural conditions? How do distributional heterogeneities in the consequences of an adverse event impede collective action to address it? Based on an understanding of their co-constituted elements, can general typologies of water systems and management strategies emerge?

We need more convergence in the ways that different disciplines (in particular hydrology, economics, public policy, and political science) formulate problems so that knowledge can accumulate across cases. Social scientists are encouraged to develop typologies of governance failures to generalize findings. They could also go beyond characterizing individual and collective decisions and cooperation dynamics and trace the effect of these social dynamics on natural systems. Finally, social scientists can address the paucity of comparative data on institutions. Natural scientists are encouraged to incorporate richer conceptions of social systems, in particular by considering the role that institutions play in water systems as distinct from the behavior of individuals such as in Anderies et al. (2006), Souza Filho et al. (2008), or Dell'Angelo et al. (2018). Process hydrologists might focus on developing modeling tools that are flexible, participatory, and open to extension to allow institutional scholars and stakeholders to use them in ways that are unanticipated. These tools should streamline the inclusion of both anthropogenic and natural processes, for example, including the ability to model impervious surfaces of various roughness, urban contaminants and contagions, and hydraulic infrastructure. This inclusivity leads to a focus on the adaptive capacity of a system emanating from its institutions and infrastructure, rather than predictive models of long-term coupled dynamics. Empirically, we must overcome the challenges of combining social with hydrological and ecological data, of which the latter two measure features of a continuous spatio-temporal field, whereas the former is discrete, often static, and may not coincide with the spatial scale at which hydrological outcomes emerge. Advances in computer science and hydrological modeling can help us combine these different types of data into more integrated and causal analyses (Ferraro et al. 2019, Müller and Levy 2019). Advances in digitization of historical records, natural language processing, machine learning, and remotely sensed imagery can help us address the paucity of data on institutions and social structure (e.g., Lansing et al. 2017).

Finally, social and natural scientists are encouraged to observe and learn from the institutional responses to stress that are being attempted by water managers around the world and consider how these responses to local water challenges might be adapted across space, time, and scales. Collaborative decision-making strategies using techniques such as immersive computational tools and exploratory modeling can support interactions at the interface of science and policy, helping scientists communicate ranges of probable outcomes and helping policy makers communicate to scientists ranges of plausible decisions. In turn, this scientific research should enhance decision-support systems, as well as inform sustainability science more broadly, especially because water management is a critical element of adapting to most environmental changes.

\section{Responses to this article can be read online at: http://www.ecologyandsociety.org/issues/responses. $\mathrm{php} / 11515$}

\section{Acknowledgments:}

The workshop "Modeling and Measuring Socio-Hydrological Dynamics Across Scales" was funded by the National Science Foundation under grant 1735884.

\section{Data Availability Statement:}

No data were collected for this paper.

\section{LITERATURE CITED}

Anderies, J. M. 2015. Understanding the dynamics of sustainable social-ecological systems: human behavior, institutions, and regulatory feedback networks. Bulletin of Mathematical Biology 77(2):259-280. https://doi.org/10.1007/s11538-014-0030-z

Anderies, J. M., M. A. Janssen, and E. Ostrom. 2004. A framework to analyze the robustness of social-ecological systems from an institutional perspective. Ecology and Society 9(1):18. https://doi. org/10.5751/ES-00610-090118

Anderies, J. M., P. Ryan, and B. H. Walker. 2006. Loss of resilience, crisis, and institutional change: lessons from an intensive agricultural system in southeastern Australia. Ecosystems 9(6):865-878. https://doi.org/10.1007/s10021-006-0017-1

Baisa, B., L. W. Davis, S. W. Salant, and W. Wilcox. 2010. The welfare costs of unreliable water service. Journal of Development Economics 92(1):1-12. https://doi.org/10.1016/j.jdeveco.2008.09.010

Beck, M. B. 1987. Water quality modeling: a review of the analysis of uncertainty. Water Resources Research 23(8):1393-1442. https://doi.org/10.1029/WR023i008p01393 
Boone, C. 2014. Property and political order in Africa: land rights and the structure of politics. Cambridge University Press, Cambridge, UK. https://doi.org/10.1017/CBO9781139629256

Brelsford, C., J. Lobo, J. Hand, and L. M. A. Bettencourt. 2017. Heterogeneity and scale of sustainable development in cities. Proceedings of the National Academy of Sciences 114 (34):8963-8968. https://doi.org/10.1073/pnas.1606033114

Brewer, J., R. Glennon, A. Ker, and G. Libecap. 2007. Transferring water in the American West: 1987-2005. University of Michigan Journal of Law Reform 40(4):1021-1053. [online] URL: https:// repository.law.umich.edu/mjlr/vol40/iss $4 / 8$

Brown, C., and U. Lall. 2006. Water and economic development: the role of variability and a framework for resilience. Natural Resources Forum 30(4):306-317. https://doi.org/10.1111/ j.1477-8947.2006.00118.x

Coman, K. 2011. Some unsettled problems of irrigation (1911). American Economic Review 101(1):36-48. https://doi.org/10.1257/ aer.101.1.36

Davies, E. G. R., and S. P. Simonovic. 2011. Global water resources modeling with an integrated model of the socialeconomic-environmental system. Advances in Water Resources 34(6):684-700. https://doi.org/10.1016/j.advwatres.2011.02.010

Dell'Angelo, J., M. C. Rulli, and P. D'Odorico. 2018. The global water grabbing syndrome. Ecological Economics 143:276-285. https://doi.org/10.1016/j.ecolecon.2017.06.033

Di Baldassarre, G., M. Kooy, J. S. Kemerink, and L. Brandimarte. 2013. Towards understanding the dynamic behaviour of floodplains as human-water systems. Hydrology and Earth System Sciences 17(8):3235-3244. https://doi.org/10.5194/hess-17-3235-2013

Di Baldassarre, G., H. Kreibich, S. Vorogushyn, J. Aerts, K. Arnbjerg-Nielsen, M. Barendrecht, P. Bates, M. Borga, W. Botzen, P. Bubeck, B. De Marchi, C. Llasat, M. Mazzoleni, D. Molinari, E. Mondino, J. Mård, O. Petrucci, A. Scolobig, A. Viglione, and P. J. Ward. 2018. Hess opinions: an interdisciplinary research agenda to explore the unintended consequences of structural flood protection. Hydrology and Earth System Sciences 22(11):5629-5638. https://doi.org/10.5194/hess-22-5629-2018

Di Baldassarre, G., A. Viglione, G. Carr, L. Kuil, K. Yan, L. Brandimarte, and G. Blöschl. 2015. Debates-Perspectives on socio-hydrology: capturing feedbacks between physical and social processes. Water Resources Research 51(6):4770-4781. https://doi. org/10.1002/2014WR016416

Elshafei, Y., M. Sivapalan, M. Tonts, and M. R. Hipsey. 2014. A prototype framework for models of socio-hydrology: identification of key feedback loops and parameterisation approach. Hydrology and Earth System Sciences 18(6):2141-2166. https://doi.org/10.5194/hess-18-2141-2014

Ferraro, P. J., J. N. Sanchirico, and M. D. Smith. 2019. Causal inference in coupled human and natural systems. Proceedings of the National Academy of Sciences 116(12):5311-5318. https://doi. org/10.1073/pnas. 1805563115

Fishman, R. M., T. Siegfried, P. Raj, V. Modi, and U. Lall. 2011. Over-extraction from shallow bedrock versus deep alluvial aquifers: reliability versus sustainability considerations for India's groundwater irrigation. Water Resources Research 47(6): W00L05. https://doi.org/10.1029/2011WR010617

Flörke, M., C. Schneider, and R. I. McDonald. 2018. Water competition between cities and agriculture driven by climate change and urban growth. Nature Sustainability 1(1):51-58. https://doi.org/10.1038/s41893-017-0006-8

Garrick, D., S. M. Whitten, and A. Coggan. 2013. Understanding the evolution and performance of water markets and allocation policy: a transaction costs analysis framework. Ecological Economics 88:195-205. https://doi.org/10.1016/j.ecolecon.2012.12.010

Geels, F. W., and J. Schot. 2007. Typology of sociotechnical transition pathways. Research Policy 36(3):399-417. https://doi. org/10.1016/j.respol.2007.01.003

Gohari, A., A. Mirchi, and K. Madani. 2017. System dynamics evaluation of climate change adaptation strategies for water resources management in central Iran. Water Resources Management 31(5):1413-1434. https://doi.org/10.1007/s11269-017-1575$\underline{Z}$

Heikkila, T., E. Schlager, and M. W. Davis. 2011. The role of crossscale institutional linkages in common pool resource management: assessing interstate river compacts. Policy Studies Journal 39(1):121-145. https://doi.org/10.1111/j.1541-0072.2010.00399. $\underline{\mathrm{X}}$

Hering, D., L. Carvalho, C. Argillier, M. Beklioglu, A. Borja, A. C. Cardoso, H. Duel, T. Ferreira, L. Globevnik, J. Hanganu, S. Hellsten, E. Jeppesen, V. Kodeš, A. Lyche Solheim, T. Nōges, S. Ormerod, Y. Panagopoulos, S. Schutz, M. Venohr, and S. Birk. 2015. Managing aquatic ecosystems and water resources under multiple stress - an introduction to the MARS project. Science of the Total Environment 503-504:10-21. https://doi.org/10.1016/ j.scitotenv.2014.06.106

Holling, C. S. 1973. Resilience and stability of ecological systems. Annual Review of Ecology and Systematics 4:1-23. https://doi. org/10.1146/annurev.es.04.110173.000245

Hornbeck, R., and P. Keskin. 2014. The historically evolving impact of the Ogallala aquifer: agricultural adaptation to groundwater and drought. American Economic Journal: Applied Economics 6(1):190-219. https://doi.org/10.1257/app.6.1.190

Lansing, J. S., S. Thurner, N. N. Chung, A. Coudurier-Curveur, Ç. Karakaş, K. A. Fesenmyer, and L. Y. Chew. 2017. Adaptive self-organization of Bali's ancient rice terraces. Proceedings of the National Academy of Sciences 114(25):6504-6509. https://doi. org/10.1073/pnas.1605369114

Li, C., X. Cheng, N. Li, X. Du, Q. Yu, and G. Kan. 2016. A framework for flood risk analysis and benefit assessment of flood control measures in urban areas. International Journal of Environmental Research and Public Health 13(8):787. https://doi. org/10.3390/ijerph13080787

Libecap, G. D. 2011. Institutional path dependence in climate adaptation: Coman's "Some Unsettled Problems of Irrigation". American Economic Review 101(1):64-80. https://doi.org/10.1257/ aer.101.1.64

Liu, J., T. Dietz, S. R. Carpenter, M. Alberti, C. Folke, E. Moran, A. N. Pell, P. Deadman, T. Kratz, J. Lubchenco, E. Ostrom, Z. 
Ouyang, W. Provencher, C. L. Redman, S. H. Schneider, and W. W. Taylor. 2007. Complexity of coupled human and natural systems. Science 317(5844):1513-1516. https://doi.org/10.1126/ science. 1144004

Lubell, M., G. Robins, and P. Wang. 2014. Network structure and institutional complexity in an ecology of water management games. Ecology and Society 19(4):23. https://doi.org/10.5751/ ES-06880-190423

Madani, K., O. M. Rouhani, A. Mirchi, and S. Gholizadeh. 2014. A negotiation support system for resolving an international transboundary natural resource conflict. Environmental Modelling and Software 51: 240-249. https://doi.org/10.1016/j.envsoft.2013.09.029

Merz, B., S. Vorogushyn, U. Lall, A. Viglione, and G. Blöschl. 2015. Charting unknown waters - on the role of surprise in flood risk assessment and management. Water Resources Research 51 (8):6399-6416. https://doi.org/10.1002/2015WR017464

Müller, M. F., and M. C. Levy. 2019. Complementary vantage points: integrating hydrology and economics for sociohydrologic knowledge generation. Water Resources Research 55(4):2549-2571. https://doi.org/10.1029/2019WR024786

Nelson, M. C., K. Kintigh, D. R. Abbott, and J. M. Anderies. 2010. The cross-scale interplay between social and biophysical context and the vulnerability of irrigation-dependent societies: archaeology's long-term perspective. Ecology and Society 15 (3):31. https://doi.org/10.5751/ES-03389-150331

Olsson, L., and A. Jerneck. 2018. Social fields and natural systems: integrating knowledge about society and nature. Ecology and Society 23(3):26. https://doi.org/10.5751/ES-10333-230326

Ostrom, E. 1993. Design principles in long-enduring irrigation institutions. Water Resources Research 29(7):1907-1912. https:// doi.org/10.1029/92WR02991

Polasky, S., S. R. Carpenter, C. Folke, and B. Keeler. 2011. Decision-making under great uncertainty: environmental management in an era of global change. Trends in Ecology and Evolution 26(8):398-404. https://doi.org/10.1016/j.tree.2011.04.007

Preiser, R., R. Biggs, A. De Vos, and C. Folke. 2018. Socialecological systems as complex adaptive systems: organizing principles for advancing research methods and approaches. Ecology and Society 23(4):46. https://doi.org/10.5751/ES-10558-230446

Quinn, J. D., P. M. Reed, M. Giuliani, A. Castelletti, J. W. Oyler, and R. E. Nicholas. 2018. Exploring how changing monsoonal dynamics and human pressures challenge multireservoir management for flood protection, hydropower production, and agricultural water supply. Water Resources Research 54 (7):4638-4662. https://doi.org/10.1029/2018WR022743

Schlüter, M., K. Orach, E. Lindkvist, R. Martin, N. Wijermans, Ö. Bodin, and W. J. Boonstra. 2019. Toward a methodology for explaining and theorizing about social-ecological phenomena. Current Opinion in Environmental Sustainability 39:44-53. https:// doi.org/10.1016/j.cosust.2019.06.011

Scholz, J. T., and C.-L. Wang. 2006. Cooptation or transformation? Local policy networks and federal regulatory enforcement. American Journal of Political Science 50(1):81-97. https://doi.org/10.1111/j.1540-5907.2006.00171.x
Sivapalan, M., and G. Blöschl. 2015. Time scale interactions and the coevolution of humans and water. Water Resources Research 51(9):6988-7022. https://doi.org/10.1002/2015WR017896

Souza Filho, F. A., U. Lall, and R. La Laina Porto. 2008. Role of price and enforcement in water allocation: insights from game theory. Water Resources Research 44(12):W12420. https://doi. org/10.1029/2007WR006163

Srinivasan, V., E. F. Lambin, S. M. Gorelick, B. H. Thompson, and S. Rozelle. 2012. The nature and causes of the global water crisis: syndromes from a meta-analysis of coupled human-water studies. Water Resources Research 48(10):W10516. https://doi. org/10.1029/2011WR011087

Tisdell, J. G. 2003. Equity and social justice in water doctrines. Social Justice Research 16(4):401-416. https://doi.org/10.1023/ A:1026365700255

Xepapadeas, A. 2011. The economics of non-point-source pollution. Annual Review of Resource Economics 3:355-373. https://doi.org/10.1146/annurev-resource-083110-115945

Zeitoun, M., B. Lankford, T. Krueger, T. Forsyth, R. Carter, A. Y. Hoekstra, R. Taylor, O. Varis, F. Cleaver, R. Boelens, L. Swatuk, D. Tickner, C. A. Scott, N. Mirumachi, and N. Matthews. 2016. Reductionist and integrative research approaches to complex water security policy challenges. Global Environmental Change 39:143-154. https://doi.org/10.1016/j.gloenvcha.2016.04.010 